\title{
Implementation of Blended Learning in Vocational Student's to Achieve HOT Skills (V-HOTS)
}

\author{
Sukatiman*, Muhammad Akhyar, Siswandari, Roemintoyo \\ Doctoral Program of Educational Science Department, Faculty of Education and Teacher Training, Sebelas Maret University, \\ Indonesia
}

Received December 9,2019; Revised February 10, 2020; Accepted February 25, 2020

Copyright $@ 2020$ by authors, all rights reserved. Authors agree that this article remains permanently open access under the terms of the Creative Commons Attribution License 4.0 International License

\begin{abstract}
Higher-Order Thinking Skills (HOTS) have already become a hot problem in the world of education, especially in developing country like Indonesia. The problem is that the teachers and the students have not been accustomed to processing and evaluating learning with a model that guarantees the creation of HOTS. This study aims to apply suitable concepts of learning in higher education- vocational. The study was conducted in 2 classes where the students had taken of the Basics of Geomatics. The learning process and evaluation involve the uses of Edmodo media application program, strengthtening to blended learning. The data collection phase was conducted by providing a questionnaire to evaluate the formation of the student's HOTS. The questionnaire results were analyzed using the paired samples t-test by SPSS program. The decision: There was a difference score between class $\mathrm{A}$ using blended learning and class B not using blended learning (p-value $=0.015<$ 0.05 ). The study concluded that the blended learning model can increase student's HOTS in higher education-vocational (V-HOTS).
\end{abstract}

Keywords Blended Learning's Model, ICT Support, Vocational HOTS

\section{Introduction}

Geomatics/ Survey and Mapping studies are currently playing an increasingly important role in providing supporting data for planning that is fast, accurate and broad, and is a necessity in the construction industry. The development of civil fields such as buildings, highways, dams, airports, etc. is closely related to map-based planning. The needs of surveyors can be met in part from vocational high school graduates majoring in Civil Engineering and from Construction Engineering Education
(PTB) graduates who also receive Geomatics materials. To meet the needs of the field, vocational graduates who can solve problems (V-HOTS) in the field are needed. How is the profile of the new students of the PTB study program in terms of their learning outcomes in vocational high schools?

To find out their initial abilities, a pretest was conducted on the college students taking the Basics of Geomatics in 2016. The test is an essay-type test consisting of 3 questions, with the levels of difficulty starting from the easy level (C1-C2) calculating the area of a right triangle, medium level (C3-C4) calculating the sides of a non-right triangle and the area of the triangle, to the difficult questions (C5-C6) determining the unknown angle and calculating the length of the sides and the area of several combined triangles (polygons). 32 college students took the pretest, consisting of 27 senior high school graduates and 5 vocational high school graduates background.

The pretest results of the students with a senior high school background (table 1) show that the success rate in solving easy questions is $92.6 \%$, with the moderate questions (C3-C4) $74 \%$ and the hard questions $0 \%$.

To find out the competencies of the students with a vocational background in construction, a pretest was carried out by the questions of calculating the area of a right triangle, filling in the reading signs, calculating the height difference with a plastic hose, and knowing the theodolite.

Table 1. Pretest Result of Applied Mathematics at college students of High School Background

\begin{tabular}{|c|c|c|c|}
\hline \multirow{2}{*}{$\begin{array}{c}\text { Student Cognitive } \\
\text { Ability }\end{array}$} & \multicolumn{2}{|c|}{ Score } & \multirow{2}{*}{$\begin{array}{c}\text { Completeness } \\
\text { Percentage }\end{array}$} \\
\cline { 2 - 4 } & Passed & Failed & $92.6 \%$ \\
\hline C1-C2 & 25 & 2 & $74 \%$ \\
\hline C3-C4 & 20 & 7 & $0 \%$ \\
\hline 5-C6 & 0 & 27 & 27 \\
\hline Number of students & \multicolumn{3}{|c|}{} \\
\hline
\end{tabular}


The pretest results of the students with a senior high school background show that the success rate in solving easy questions is $92.6 \%$, with the moderate questions (C3-C4) $74 \%$ and the hard questions $0 \%$.

To find out the competencies of the students with a vocational background in construction, a pretest was carried out by the questions of calculating the area of a right triangle, filling in the reading signs, calculating the height difference with a plastic hose, and knowing the theodolite.

Table 2. Cognitive pretest result of Vocational students with construction background

\begin{tabular}{|c|c|c|c|}
\hline \multirow{2}{*}{$\begin{array}{c}\text { Student Cognitive } \\
\text { Ability }\end{array}$} & \multicolumn{2}{|c|}{ Score } & \multirow{2}{*}{$\begin{array}{c}\text { Completeness } \\
\text { Percentage }\end{array}$} \\
\cline { 2 - 3 } & Passed & Failed & $100 \%$ \\
\hline C1-C2 & 5 & 0 & $60 \%$ \\
\hline C3-C4 & 3 & 2 & $0 \%$ \\
\hline C5-C6 & 0 & 5 & 5 \\
\hline Number of students & \multicolumn{3}{|c}{5} \\
\hline
\end{tabular}

Remark: Pretest questions were documented by the researcher.

The test results table 2 show that $100 \%$ of the students with a vocational background can only do the easy questions (C1-C2), while $60 \%$ of them can do moderate questions (C2-C4), and no student can do difficult questions (C5-C6). It can be concluded that the students still have not mastered V-HOTS. Dick, W., \& Carey, (2009) [1] states that initial ability is a special skill possessed by students that they must be able to demonstrate before participating in certain learning activities. The student's initial knowledge can be used as a reference for lecturers to design appropriate learning so that students can get progress in their learning.

\subsection{Learning Based on Vocational Higher Order Thinking Skills (V-HOTS)}

Higher-order thinking skills (HOTS) are thinking activities that involve a high level of cognitive hierarchy from Bloom's taxonomy of thinking. HOTS is progressing very rapidly in this 21st-century learning. There is no doubt that the development of higher order thinking skills in students is important. However, for this to happen, the teachers themselves need to acquire and practice these skills [2]. In contrast to the studies in general that make students the subject of learning, [3] puts forward the equality of responsibility of lecturers and students in the transfer of knowledge.

The modern learning approach places student achievement at the center of development and quality assurance [4] because the goal of HOTS learning will prepare students to succeed in challenging the real-world today.

\section{How to Realize This HOTS in Learning?}

Many teachers feel that they have assessed the students'
HOTS, but they have not $[5 ; 6]$. The answer to the question about realizing HOTS is to integrate this level of thinking in the learning and evaluation process. In the learning process, 5M scientific learning (observing, questioning, experimenting, asscociating, communicating) should be involved. The Regulation of the Minister Eduction and Culture of Republic Indonesia [7] requires the $5 \mathrm{M}$ learning elements to be included in the lesson plan, which can be described as follows:

There are five (5) elements of the learning process that focus on student activity, and learning models. These 5 elements are the discovery process and most likely to be found with the Problem-Based Learning (PBL) process.

With HOTS, it allows students to apply knowledge, skills and values to reason and reflect to solve problems, make decisions, innovate and try to create something in developing skills [8].

In the vocational field, it is not necessarily obtained without practicing with the mastery of adequate equipment to get HOTS. To maintain the achievement of students' competencies as well as the use of equipment continuously, guidance (Scaffolding) is needed before students construct their knowledge. Therefore, students in the vocational field have a specialty in getting HOTS, by combining guidance and problem solving (Scff-PBL), in which the learning outcomes obtained are the vocational high-order thinking methods (V-HOTS).

\subsection{Blended Learning}

The utilization of ICT in learning is not just about providing computers or connecting to the internet, but lecturers must also go in and dive deeper into these technologies to improve the effectiveness of the learning process [9].

The results of the study of Heitink, et al [10] show that the use of ICT in facilitating learning (student activities, classroom management, mentoring strategies) of the elementary school teachers is very helpful in making the students active.

In the future, students will have a different way of thinking from the previous generation. The result of the study of Phumeechanya [11] shows that e-learning is the facility that helps students to be able to learn anywhere, anytime, so that this learning is in line with constructivist theory.

ICT in the form of e-learning media is a technological tool to assist, and facilitate communication, delivery and processing of information through electronic means [12]. [13] It states that distance learning (e-learning) can enhance and precipitate knowledge and provide broad access to increase students' participation. Harandi's [14] findings show that when teachers implement e-learning, the students' motivation will improve. Distance learning is useful for overcoming limitations of classrooms as well as distance and time constraints in the implementation of teaching and learning activities. However, Gunn and Pitt, 
[15] conclude that students do not want that face-to-face learning is replaced too much by computer-based learning packaging.

The lecturer is an expert in his field, but it would be very good if he could improve and modernize his learning with Information and Communication Technology (ICT) [16]. ICT is closely related to the needs of students who follow the trend of the millennial generation (Gen-Y), especially with the development of internet advances lately. There is one type of learning activity in addition to presentations, discussions, and quizzes, namely e-learning activities such as chatting, forums, sending files, which need strategies to achieve the goals [17].

The design of a blended learning environment contains four main challenges: (1) combining flexibility, (2) stimulating interaction, (3) facilitating student learning processes, and (4) encouraging affective learning climate [18]. Based on the t-test result of the study of Tseng, H., and Walsh, E. J. [19] about the achievement between face-to-face learning and blended learning, $\mathrm{M}=84.49$ is with $\mathrm{SD}=10.19$. The highest score for blended learning compared to face-to-face learning is $\mathrm{M}=82.13$ with $\mathrm{SD}=$ $10.50, \mathrm{t} 137=1.31, \mathrm{p}=\mathrm{ns}$ with no significant difference. Thus, it can be concluded that despite of its not significance, blended learning can achieve better results than face-to-face learning.

The result of the study [20] on 86 fifth-grade students and 80 sixth-grade students shows that the creation of a technology-enriched classroom environment (ICT) has a positive effect on the acquisition of high-order thinking skills (HOTS) of students.

From many of the results of the study above, it can be summarized that good learning must be involved in the use of ICT to provide learning flexibility, but students do not want face-to-face learning to be replaced too much. Thus, in practical learning, in addition to the main equipment, the use of mixed learning is also important as support for the creation of V-HOTS. Blended learning in this study are 1) the use of ICT-based survey and mapping equipment, such as the use of Total Station (TS), and handheld Global Positioning System (GPS) tools that are updated, so that learning is expected to have link and match with the industrial world, and 2) the application of Edmodo, as a media to strengthen face-to-face learning. One week before the lecture was held, material contracted by lecturers and students had been uploaded on Edmodo application in the form of a Pdf file. Students are notified of upcoming material. With the convenience of students to explore the material before lecturing, it is hoped that learning will be more active, 3) use blended learning to evaluate (middle semester and end semester and to check students' portfolio of practice report.

\subsection{Blended Learning in Geomatics Subject}

The main objective of the research is to improve the quality of the students' learning, by applying ICT on the scaffolding Problem-Based Learning (Scf-PBL) model. This model in its implementation combines the skills of a tutor (lecturer) and tutee (senior student). Tutee is empowered to support students when they use geomatics equipment so that the equipment be operated more proper and safe. The implementation in practice gives more procedural guidance (Scaffolding), but the implementation of PBL in the learning process, is expected to produce higher-order thinking skills (HOTS). The development of the Scff-PBL integration model can support and provide innovative learning variations convenient to the needs of millennial students. The task of lecturer in learning strategy includes grouping students fairly, preparing media, student activity, scheduling, evaluating and feedback, lecturer's reflections on improving student' progress.

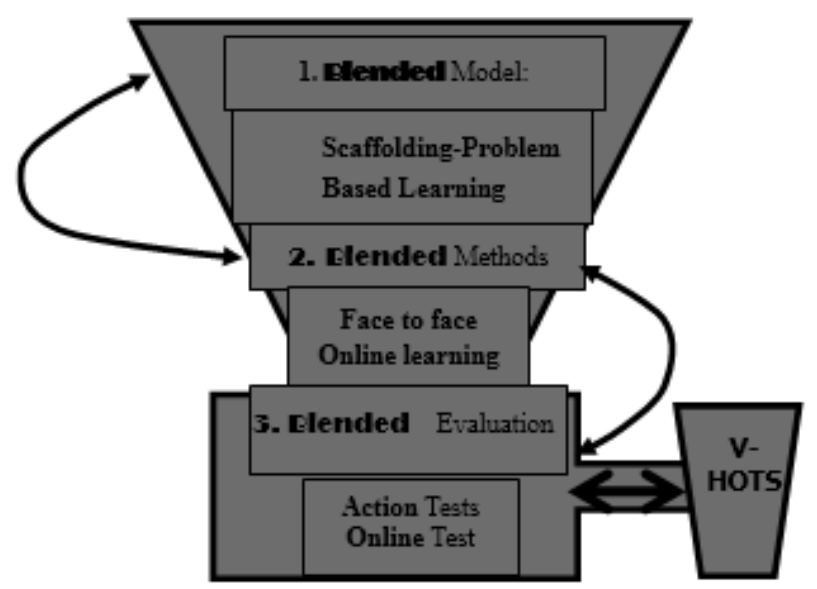

Figure 1. The Concept of Blended Learning in Geomatics.

Figure 1. Illustrates the application of blended learning to obtain student' vocational higher-order thinking (V-HOT). 1) Blended model, which is by applying a coaching model with problem-based learning (PBL), 2) Blended methods, utilizing face-to-face learning methods and online methods, and 3) Blended evaluation, applying action evaluation learning and evaluating online learning.

\subsection{V-HOTS Emphasis on Learning Evaluation}

The lack of consistent emphasis on the experimental design shown in the attitude, goal, and assessment method domains seems to indicate that the approach to problem-solving must be emphasized more [21] while the evaluation of the questions developed should not be limited to the level of applying (C3), but to analyzing (C4), evaluating (C5) and creating (C6) [22].

From the background described above, this study has the following objectives: 1) How to apply an effective blended learning model to improve student's V-HOTS. 2) Finding out the extent of the successful implementation of blended learning in Geomatics learning towards the 
achievement of student’s V-HOTS.

\subsection{Learning Evaluation}

The evaluations that can guarantee the formation of V-HOTS done in Geomatics learning are theoretical and practical (action) tests. There are four (4) tests used in this study, namely 1) online-based multiple-choice pretest, 2) action test (practice test), 3) online-based basic competency test, and 4) portfolio of practice reports.

The objective test (multiple choice) is based on the outline of the 30 question items, considering the formation of lower to higher order thinking (C1-C6) as shown in table 3:

Table 3. Formation of Student's HOTS on Basics of Geomatics

\begin{tabular}{|c|c|c|c|}
\hline No. & Category & HOTS Levels & $\begin{array}{c}\text { Number } \\
\text { of Items }\end{array}$ \\
\hline 1 & Knowledge & C1 & 10 \\
\hline 2 & Understanding & C2 & 5 \\
\hline 3 & Applying & C3 & 4 \\
\hline 4 & Analyzing & C4 & 7 \\
\hline 5 & Synthesizing & C5 & 2 \\
\hline 6 & Evaluating & C6 & 2 \\
\hline \multicolumn{3}{|c|}{ Total questions } & 30 \\
\hline
\end{tabular}

There were various kinds of learning evaluations carried out to improve the students' learning outcomes, one of which was by providing online quizzes. The advantage of this online assessment is that the students' work can be known immediately and used as a reflective material for the lecturer on the material given.

\section{Research Methodology}

The approach in this study is quantitative research, with the type of the study in the form of Classroom Action Research (CAR) conducted at Universitas Sebelas Maret Surakarta for 6 months involving 2 classes of Survei and mapping/ Geomatics learning. The study subjects consisted of 62 students. Class A is an experimental class consist of 31 students and class B is a control class consist of 31 students. The research was divided into 4 stages: Analysis, Design, Development, Implementation, and Evaluation (ADDIE) [21]. Each step involves the use of media that supports the material upload in the Edmodo program, where the students can browse and get data using a mobile device.
The data collection stage was carried out by administering a questionnaire to assess what the lecturer had done to improve the student's V-HOTS. In the questionnaire, the students filled out the form based on a Likert scale by selecting 5 available answers, score 1 for very unsatisfactory, 2 for unsatisfactory, 3 for quite satisfactory, 4 for satisfactory, and 5 for very satisfactory.

The questionnaire questions consist of 4 criteria as shown in table 4:

Table 4. Questionnaire organization

\begin{tabular}{|c|c|c|c|}
\hline & Source & Category & $\begin{array}{c}\text { Number of } \\
\text { items }\end{array}$ \\
\hline A & {$[23] ;[10]$} & $\begin{array}{c}\text { Scff-PBL model in HOTS } \\
\text { learning process }\end{array}$ & 10 \\
\hline B & {$[24]$} & $\begin{array}{c}\text { Application of ICT in } \\
\text { learning }\end{array}$ & 10 \\
\hline C & {$[23]$} & Teamwork & 4 \\
\hline D & & $\begin{array}{c}\text { Student learning evaluation } \\
\text { oriented to HOTS }\end{array}$ & 10 \\
\hline \multicolumn{4}{|c|}{ Number of questionnaire items } \\
\hline
\end{tabular}

\section{Result and Discussion}

Extensive test results of students' grades consist of the experimental class and the control class. Scores are taken twice in the middle of the semester (UTS) and the end of the semester (UAS).

Based on the type of sample above, then statistic test used paired- sample t-test. The absolute requirement for parametric statistical tests is the normality test. Data normality test used SPSS V.23.

Based on the output data, the data used is the Kolmogorov-Smirnov sig column, because the data were 62 respondents (more than 30). From the significance value of class (A pre-test $=0.200$, class A posttest $=0.147$, class $\mathrm{B}$ pre-test $=0.086$, and class $\mathrm{B}$ posttest $=0.116)>$ 0.05 , it can be concluded that the data is normally distributed, so the parametric test can continue to define where both samples are there significantly different. The statistic test used a paired sample t-test.

\section{Basic Decision Making, [25]:}

1. If the significance (p-value) $<0.05$, then there is a significant difference between learning outcomes in class A and B.

2. If the significance ( $\mathrm{p}$ value) $>0.05$, there is no significant difference between learning outcomes in class A and B. 
Table 5. Statistical result analysis

\begin{tabular}{|c|c|c|c|c|c|c|c|c|c|}
\hline & \multicolumn{2}{|c|}{$\begin{array}{c}\text { Levene's Test for } \\
\text { Equality of } \\
\text { Variances } \\
\end{array}$} & \multicolumn{7}{|c|}{ t-test for Equality of Means } \\
\hline & \multirow[t]{2}{*}{$\mathrm{F}$} & \multirow{2}{*}{ Sig. } & \multirow{2}{*}{$\mathrm{t}$} & \multirow{2}{*}{$\mathrm{df}$} & \multirow{2}{*}{ p-value } & \multirow{2}{*}{ Mean Difference } & \multirow{2}{*}{$\begin{array}{l}\text { Std. Error } \\
\text { Difference }\end{array}$} & \multicolumn{2}{|c|}{$\begin{array}{c}\text { 95\% Confidence Interval } \\
\text { of the Difference }\end{array}$} \\
\hline & & & & & & & & Lower & Upper \\
\hline \multirow{2}{*}{$\begin{array}{c}\text { Learning outcomes in } \\
\text { Geomatics }\end{array}$} & 1.889 & , 174 & -2.492 & 60 & .015 & -6.51613 & 2.61480 & -11.746 & -1.285 \\
\hline & & & -2.492 & 55.96 & .016 & -6.51613 & 2.61480 & -11.754 & -1.277 \\
\hline
\end{tabular}

The statistical analysis with SPSS (table-5) shows that the significance $(p$ value $=0.016)<0.05$.

Decision: There is a difference in scores between class A which applies blended learning and class B which does not. Thus, it is concluded that blended learning significantly improves students’ HOTS.

In the context of the teaching and learning process, with a mobile device, it allows teachers and students to overcome class time and physical limits as information is everywhere and no longer limited to specific times or places to learn [26] Innovation is also compulsory for lecturers to develop media in line with what the students want, namely online learning. In the current era, blended learning is the most preferred media for students [27].

This study can indeed improve students' learning outcome, significantly. The analysis results show that although 8 instructors are teaching the material of the Basics of Geomatics with different competencies, teaching methods, and intensity of meetings with students, the students get clear when they need help. Further, many items at the questionnaire still need to be increased in pedagogy. This can be seen from the questionnaire items no. 3 (Does the lecturer provide a stimulus for creative thinking in each lesson?), no. 4 (Does the learning model applied by the lecturer can evoke clear concepts and good solutions and have real goals, criteria and standards?), no. 5 (Does the learning process given by the lecturer not integrate the level of adult communication, problem-solving, and critical-thinking skills?), and no: 10 (Does the lecturer not lead brain storming/debates in class? How to solve a problem in a topic? The score achieved from the questionnaire is only 3 of 5 (Neutral). This indicates a mismatch with the theory of [15], who conducted an online learning study on K-12 (senior high school level) showing that teacher training knowledge (pedagogy) and material content were the highest, at the same time teachers feel less confident in the technology domain (ICT). This can be interpreted that the teacher has not fully mastered the technology domain as a profession. The reflection that must be done is to give the results of this questionnaire to the lecturers to improve their abilities in pedagogy.

\section{Conclusions}

The results of this study concluded that the use of ICT in the form of practical equipment, multimedia, and blended learning models has great potential in achieving higher-order thinking Skills vocational students (V-HOTS). The Utilization of ICT is also carried out to determine the student's initial competency (pretest) so that the lecturer can immediately reflect on the results of student achievement. the study is consistent with the research of Taylor and Ghani [28] which reveals that e-learning activities support and complement face-to-face classes, and thus the combined effects have a clear impact on learning.

\section{REFERENCES}

[1] L. Dick, W., \& Carey, The systematic design of instruction, Seventh ed. Kevin M Davis, 2009.

[2] M. Barak and Y. J. Dori, "Enhancing higher order thinking skills among inservice science teachers via embedded assessment,” J. Sci. Teacher Educ., vol. 20, no. 5, pp. 459-474, 2009.

[3] S. yin S. Yeung, "Conception of teaching higher order thinking: perspectives of Chinese teachers in Hong Kong," Curric. J., vol. 26, no. 4, pp. 553-578, 2015.

[4] T. El-maaddawy, "Innovative assessment paradigm to enhance student learning in engineering education," vol. 3797, no. April, pp. 1-16, 2017.

[5] S. M. Brookhart, Assess HOTS in Your Classroom. 2007.

[6] D. Peterson, J. Kromrey, A. Lewis, and J. Borg, "Clinical pedagogy: Defining and measuring the teaching of essential and higher order thinking skills,” J. Pers. Eval. Educ., vol. 6, no. 1, pp. 57-70, 1992.

[7] Regulation of The Minister of Education and Culture of the Republic of Indonesia No.103 of 2014, no. 1. Indonesia, 2014, pp. 1-11.

[8] S. Vasantha, "The Role of Higher Order Thinking Skills in Green Skill Development,” MATEC Web Conf., vol. 70, pp. 1-5, 2016.

[9] K. McKnight, K. O’Malley, R. Ruzic, M. K. Horsley, J. J. Franey, and K. Bassett, "Teaching in a Digital Age: How Educators Use Technology to Improve Student Learning,” J. Res. Technol. Educ., vol. 48, no. 3, pp. 194-211, 2016.

[10] M. Heitink, "Eliciting teachers' technological pedagogical knowledge,” vol. 33, no. 3, pp. 96-109, 2017.

[11] N. Phumeechanya, "Development of a Ubiquitous Learning 
System with Scaffolding and Problem-Based Learning Model to Enhance Problem-Solving Skills and ICT Literacy,” Int. J. e-Education, e-Business, e-Management e-Learning, vol. 3, no. 3, pp. 197-201, 2013.

[12] J. C. Brown and H.-S. Park, “The Online Journal of Distance Education and e-Learning," Online J. Distance Educ. e-Learning, vol. 3, no. 1, pp. 1-7, 2015.

[13] K. Safford and J. Stinton, "Barriers to blended digital distance vocational learning for non-traditional students," Br. J. Educ. Technol., vol. 47, no. 1, pp. 135-150, 2016.

[14] S. R. Harandi, "Effects of e-learning on Students' Motivation," Procedia - Soc. Behav. Sci., vol. 181, pp. 423-430, 2015

[15] A. Gunn and S. J. Pitt, “The effectiveness of computer-based teaching packages in supporting student learning of parasitology,” Biosci. Educ., vol. 1, no. 1, pp. 1-14, 2003.

[16] D. Hung and M. Nichani, “Constructivism and e-Learning: Balancing Between the Individual and Social Levels of Cognition,” Educ. Technol., vol. 41, no. 2, pp. 40-44, 2001.

[17] M. Al-doseri, A. Elgazzar, and A. Nouby, "A strategy for managing e-training environment's activities and its effectiveness in developing blended learning design competencies of Bahraini secondary stage female teachers," Int. J. Arts Sci., vol. 09, no. 02, pp. 1-16, 2016.

[18] R. Boelens, B. De Wever, and M. Voet, "Four key challenges to the design of blended learning: A systematic literature review,” Educ. Res. Rev., vol. 22, pp. 1-18, 2017.

[19] J. Tseng, H., \& Walsh, E. J., "Blended_versus_traditional_cou.PDF," Quarterly Review of Distance Education, vol. 17, no. 1. pp. 43-52, 2016.

[20] M. H. Hopson, R. L. Simms, and G. A. Knezek, "Using a technologically-enriched environment to improve higher-order thinking skills,” J. Res. Technol. Educ., vol. 34, no. 2, pp. 109-119, 2001.

[21] K. Tankersley, “Higher-Order Thinking,” vol. 27, no. 9, pp. 835-847, 2005.

[22] M. D. Kusuma, U. Rosidin, A. Abdurrahman, and A. Suyatna, "The Development of Higher Order Thinking Skill (Hots) Instrument Assessment in Physics Study,” IOSR J. Res. Method Educ., vol. 07, no. 01, pp. 26-32, 2017.

[23] P.-S. Chiu, Y.-H. Pu, C.-C. Kao, T.-T. Wu, and Y.-M. Huang, "An authentic learning based evaluation method for mobile learning in Higher Education,” Innov. Educ. Teach. Int., vol. 3297, no. January, pp. 1-12, 2018.

[24] K.-J. Kim and C. J. Bonk, “The Future of Online Teaching and Learning in Higher Education: The Survey Says... \{(EDUCAUSE $\}$ Quarterly) \{ltextbar\} \{EDUCAUSE\}," Educ. Q., no. 4, pp. 22-30, 2006.

[25] Siswandari, Statistika computer based. Surakarta: UNS Press, 2015.

[26] F. Moreira, M. J. Ferreira, C. P. Santos, and N. Durão, "Evolution and use of mobile devices in higher education: A case study in Portuguese Higher Education Institutions between 2009/2010 and 2014/2015,” Telemat. Informatics, vol. 34, no. 6, pp. 838-852, 2017.
[27] Sukatiman, "Framework of the Blended Learning in Vocational Study to Achieve Hot Skills,” vol. 317, no. IConProCS, pp. 239-244, 2019.

[28] M. Taylor, S. Atas, and S. Ghani, "Exploring the Experiences of Students and Professors in a Blended Learning Graduate Program,” Int. J. Mob. Blended Learn., vol. 9, no. 1, pp. 1-15, 2017. 